\title{
Effect of Different Crown Removing Procedures on the Implant Stability Quotient and Removal Torque Values of Dental Implants
}

\author{
Hakan Akin ${ }^{1}$, Yasemen Unal ${ }^{\circledR}$, Kaan Yilmazer ${ }^{3}$ \\ ${ }^{1}$ Sakarya University, Faculty of Dentistry, Department of Prosthodontics, Sakarya, Turkey. \\ ${ }^{2}$ Minister of Health, Sivas Oral and Dental Hospital, Sivas, Turkey. \\ ${ }^{3}$ Istanbul University, School of Dentistry, Department of Prosthodontics, Istanbul, Turkey.
}

Correspondence Author: Hakan Akin

E-mail: drhknkn@hotmail.com

Received: $02.09 .2020 \quad$ Accepted: 22.02.2021

\begin{abstract}
Objective: To investigate the effects of different crown-removal methods on the osseointegration of dental implants in implant-retained single crowns.

Methods: Two implants were inserted in each tibia of each New Zealand rabbit's rear legs (total of 32 implants were used). After 28 days, resonance frequency analysis was performed on the implants to detect the degree of osseointegration; 24 hours later, the sacrificed tibias were divided into 3 groups according to different crown-removal methods: crown removal with a diamond bur, the use of a spring-loaded crown remover, and the use of a pneumatic crown remover. Following the crown-removal procedures, the implants' resonance frequency analysis (RFA) values and removal torque values were measured.

Results: No significant difference in implant stability quotient (ISQ) was measured after crown removal for either group of diamond bur or group of pneumatic crown remover ( $p=0.677$ and $p=0.918$, respectively). However, there was a statistically significant difference in implant stability quotient after crown removal for group of spring-loaded crown remover $(p=0.008)$. Moreover, no significant difference was detected between the groups' removal torque values ( $p>0.05)$.

Conclusion: The crown-removal procedure has significantly unfavorable effect on the implant stability quotient values of the implants, whereas removal torque values of the implants was not affected crown-removal procedures.
\end{abstract}

Keywords: Dental implant, crown, resonance frequency analysis.

\section{INTRODUCTION}

Implant-supported fixed prosthesis is a well-documented and highly predictable treatment option with a high rate of success for replacing single or multiple missing teeth. There are two retention types for fixating a prosthetic superstructure on implant abutments: cementation and screw retention (1-6).

Cement-retained prostheses can be fabricated by conventional laboratory procedures and can be fixated on the abutment just like crowns for teeth $(7,8)$. According to a systematic review, cement-retained implant-supported fixed prosthesis presented fewer technical problems but more biological problems (such as implant failures and marginal bone loss) when compared to screw-retained implant-supported fixed prosthesis (4). In another systematic review, cement-retained implant-supported fixed prosthesis resulted in better preservation of marginal bone, fewer prosthetic complications, and higher implant survival rates when compared to screw-retained implant-supported fixed prosthesis (3).
In clinical studies, the dental implant survival rates are $89.4 \%$ for implant-supported single crowns and $86.7 \%$ for implantsupported fixed prosthesis (9-12). Thus, implant-supported fixed prosthesis need to be removed and renewed when mechanical or biological complications occur, including fracturing of the veneering ceramic or gingival recession in the aesthetic zone.

Various procedures are utilized to remove implant-supported fixed prosthesis. Conventional methods involve applying physical force on the cervical margin of the restoration with impact delivering devices (7). Manual or spring-loaded back-action instruments, spring-loaded semiautomatic or automatic devices, and pneumatic devices are used for this purpose (13). Another removal procedure is to divide a crown into two parts (mesial and distal) with cutting burs. However, there is no guideline for the clinician as to how crown removal affects the osseointegration of dental implants. Although there is no data in the literature, many prosthodontics advise 
that prostheses should be removed by cutting with diamond burs instead of crown removers to eliminate possible adverse effects of bone-implant contact (BIC). Thus, the objective of this study was to investigate the effects of different crownremoval methods on the implant stability quotient (ISQ) and removal torque value (RTV) of implants in implant-supported single crowns. The hypothesis tested was that no difference exists on the impact of the ISQ and the RTV values of dental implants after different crown-removal procedures.

\section{METHODS}

\subsection{Implants and Animals}

Thirty-two conical, calcium-incorporated titanium implants (AnyOne, MegaGen Co. Ltd., Kyungsan, South Korea) with length $7 \mathrm{~mm}$ and a diameter $3.5 \mathrm{~mm}$ were used in this study.

Eight adult male New Zealand white rabbits weighing 3.5 to $4 \mathrm{~kg}$ were used in this study. They were supplied by the same certificated center. This experiment was approved by the Animal Ethics Commission of Cumhuriyet University (protocol number: 65202830/134). Animals were operated on and housed in the Experimental Animal Laboratory of the Veterinary Faculty at Cumhuriyet University. Prior to surgery, animals were kept in individual cages on a standard diet (solid ration) with 12-hour cycles of light at a humidity of $55 \%$ to $70 \%$ and a temperature of $22^{\circ} \mathrm{C}$ to $24^{\circ} \mathrm{C}$ for 2 weeks to ensure adaptation to laboratory conditions.

\subsection{Surgical Procedure}

The rabbits were anesthetized with a combination of 50 $\mathrm{mg} / \mathrm{kg}$ ketamine (Ketalar, Eczacıbaşı, Istanbul, Turkey) administered intramuscularly and $5 \mathrm{mg} / \mathrm{kg}$ xylazine (Rompun, Bayer, Leverkusen, Germany). The rear legs of the rabbits were shaved and washed with a $70 \%$ ethanol mixture and an iodine solution. To improve analgesia and control bleeding, 1 $\mathrm{mL}$ of local anesthetic (Ultracaine DS Fort, Aventis Pharma, Turkey) was injected locally into the tibia surgical sites.

The surgical sites were exposed with an incision through the skin (Figure 1A), fascia, and periosteum at the medial surface of proximal tibias using sterile surgical techniques (Figure 1B). The osteotomy was performed on a flat surface on the lateral part of the proximal tibia using a low-speed rotary instrument under constant irrigation with sterile saline, according to the recommended surgical protocol supplied by the manufacturer. Two implants were inserted in each tibia of each rabbit's rear legs (Figure $1 \mathrm{C}$ ). Thus, each animal received four implants, and a total of 32 implants were performed on eight rabbits. In addition, a manual torque meter was used for standardization of insertion torque values, which were within the range $35 \pm 3 \mathrm{~N}$. Following the osteotomy, the surgical sites were closed in layers using Vicryl resorbable sutures (Ethicon, Somerville, NJ, USA; Figure 1D). In the postoperative period, antibiotics (Cephaxon, Toprak Ilaç, Sakarya, Turkey) and analgesics (Rimadyl, Pfizer, Istanbul,
Turkey) were injected intramuscularly for 3 days to prevent postsurgical infection and to control pain.

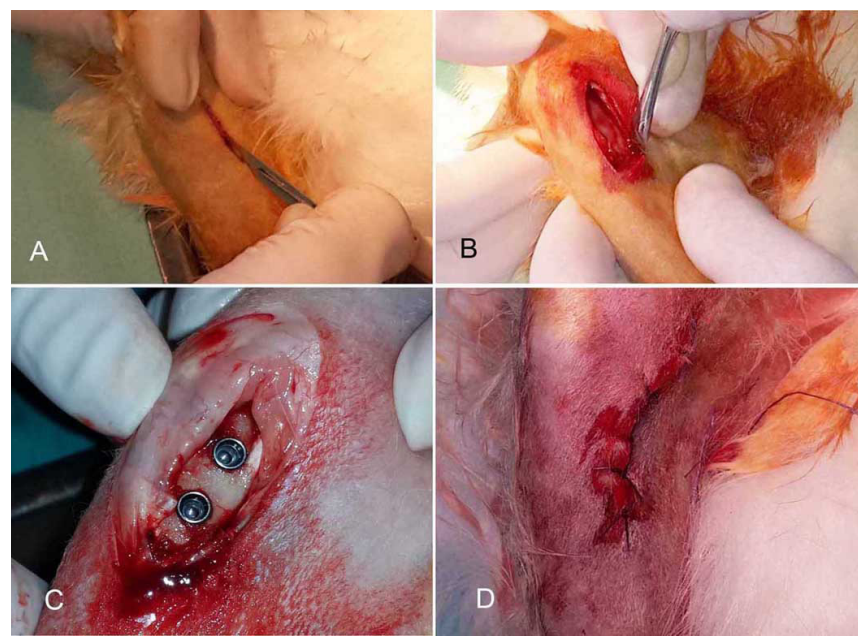

Figure 1. Surgical procedure. A.Incision through the skin; B. Elevation of fascia and periosteum; C. Inserted implants in rabbit's tibia. D. Closed surgical sites with sutures.

\subsection{Preparation of Crowns}

Thirty-two titanium abutments (MegaGen Co. Ltd., Korea) were used in this study; each abutment had a diameter of $4.5 \mathrm{~mm}$ and a length of $9 \mathrm{~mm}$ (including $3.5 \mathrm{~mm}$ gingival length). Cast plastic caps, which enable the production of identical crowns on separate implants, were also used. A buccal extension, which enables the easy placement of crown removers, was added on the plastic caps using casting wax. The conventional casting process was then carried out (Figure 2). Cobalt-chromium alloy crowns were checked on the abutments.

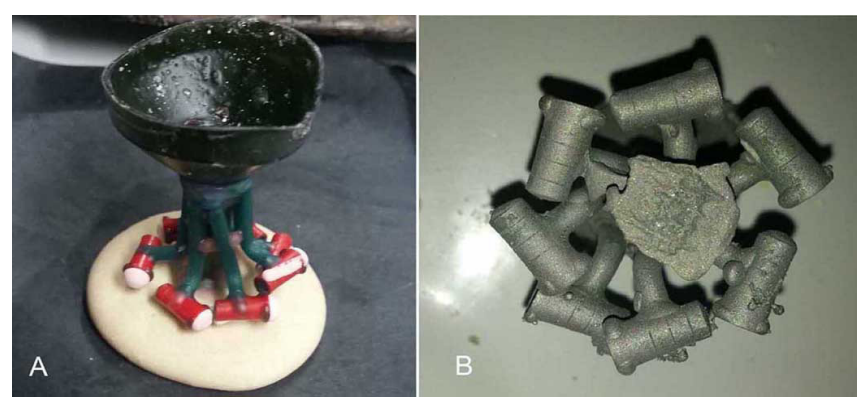

Figure 2. Production of cobalt-chromium alloy crowns.

\subsection{Resonance Frequency Analysis (RFA)}

After 4 weeks, the same surgical protocol was followed and the implants were surgically exposed, and a SmartPeg (MegaGen Co. Ltd., Korea) was screwed into each implant and tightened to approximately $5 \mathrm{~N}$ with a special wrench. The implant stability quotient (ISQ) values were measured with MegalSQ (MegaGen Co. Ltd., Korea). For each implant, the probe of the ISQ machine was held stable at a distance of approximately $2 \mathrm{~mm}$ from the SmartPeg. Two measurements 
were conducted on the mesial and distal parts of the SmartPeg, and mean ISQs were recorded (Figure 3).

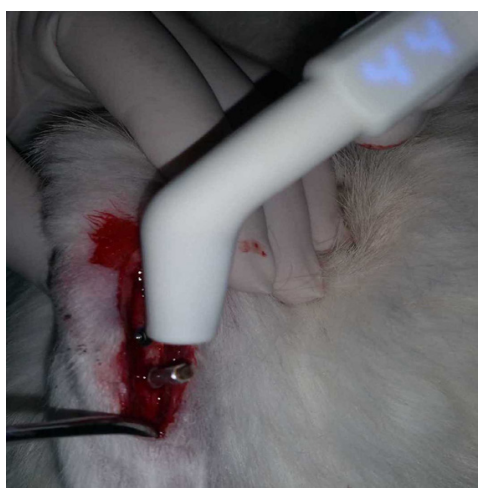

Figure 3. RFA measurement before crown removing.

\subsection{Crown Cementation}

Abutments were placed into the implants and fixed with a 25 $\mathrm{N} \cdot \mathrm{cm}$ torque using a torque wrench (MegaGen Co. Ltd., Korea) according to the manufacturer's instructions. Afterward, the crowns were cemented on the abutments with a dual-cure resin cement (MIS Crown Set, MIS Implant Technologies Ltd, Shlomi, Israel), which came in a plastic syringe and included mixing tips. Finger pressure was applied to the plastic syringe and resin cement was poured into the crowns. They were seated onto the abutments and $1 \mathrm{~kg}$ weight was placed onto the crowns. After removing the excessive resin cements, light-cure was applied.

\subsection{Crown Removal}

After 24 hours to cement the crowns, the animals were sacrificed using an intravenous overdose of ketamine (2 $\mathrm{mL}$ ) and xylazine $(1 \mathrm{~mL})$. Each animal's tibias were removed (Figure $4 \mathrm{~A}$ ) and kept in a $10 \%$ buffered formalin solution. The tibias were randomly assigned to 3 groups according to the crown-removal method applied: crown removal with a diamond bur, the use of a spring-loaded crown remover, and the use of a pneumatic crown remover.
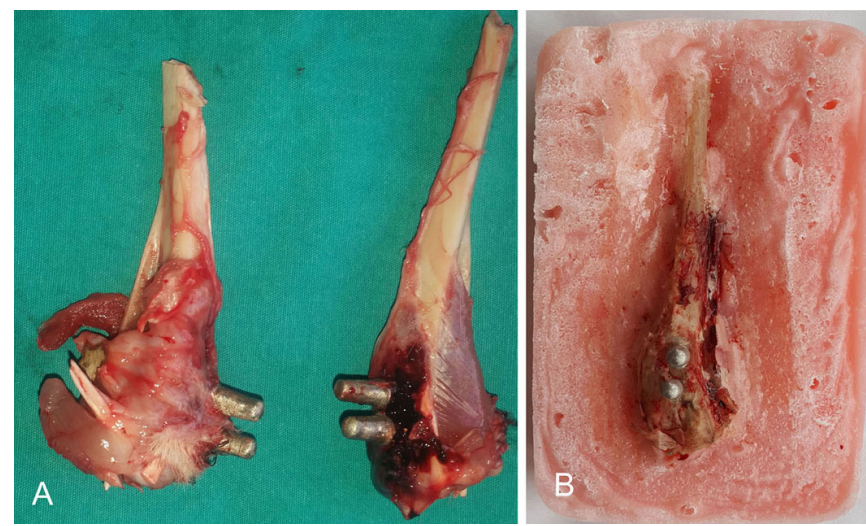

Figure 4. A. Harvested tibias. B. Embedded tibias into autopolymerizing acrylic resin.
For the group of diamond bur, the crowns were removed by cutting with a black-belt torpedo diamond bur (MDT Dental, Afula, Israel; Figure 5A). Fission of the crowns was performed at a pressure of $32 \mathrm{psi}$ and under water cooling at a constant speed of $25 \mathrm{~mL} / \mathrm{min}$. The maximum bur rotation rate was set at 400,000 $\pm 2,000 \mathrm{rpm}$. In addition, each diamond bur was used for one cut only.
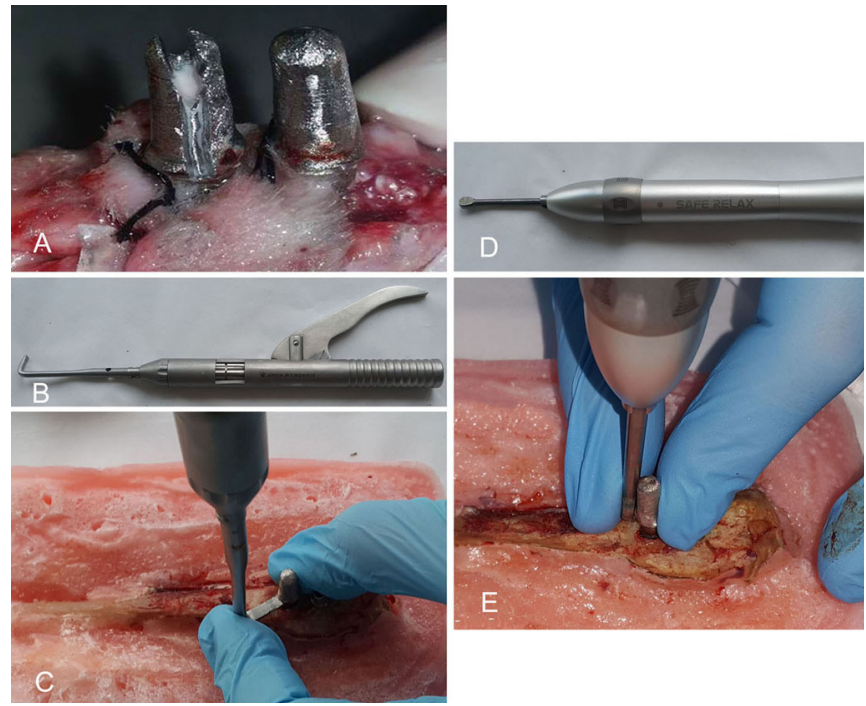

Figure 5. Crown removing methods. A. Bur-cut; B. Spring loaded back action crown remover; $C$. Application of spring loaded back action crown remover; $D$. Pneumatic crown remover; $E$. Application of pneumatic crown remover.

For the group of spring-loaded crown remover, the tibias were embedded into auto polymerizing acrylic resin (Meliodent, Bayer Dental Ltd., Newbury, UK; Figure 4B). A spring-loaded, back-action crown remover (Jensen jp1, Dental Instruments, İslamabad, Pakistan; Figure 5B) was positioned at the buccal extension of the crowns (Figure 5C). Maximum force was adjusted and delivered until the crowns were removed. The reactivation requirement of the crown remover was not needed. During activation, a second researcher achieved the stabilization of the acrylic block by using a clamp from one end of the block to the table and she also applied finger pressure on the other end of the block to prevent the movement.

For the group of pneumatic crown remover, the tibias were embedded into auto polymerizing acrylic resin (Meliodent, Bayer Dental Ltd.). A pneumatic crown remover (Saferelax, Anthogyr, Sallanches, France; Figure 5D) was used to remove this group of crowns (Figure 5E). It was plugged into the dental unit's turbine head housing, which provides compressed air for activation. The maximum force was adjusted, the tip of the remover was placed at the crowns' buccal extension, and force was delivered until removal was achieved. During activation, a second researcher achieved the stabilization of the acrylic block.

After the crowns were removed, a smart peg was screwed into each implant. The ISQs were measured again, and the data were recorded. 


\subsection{Removal Torque Test}

Following resonance frequency analysis (RFA), to evaluate implant stability, a removal torque test (RTT) was performed on the implants (Figure 6). The second researcher stabilized the acrylic blocks, and a digital torque meter (IMADA, Northbrook, IL, USA) was positioned in the direction of the implant axis. The removal torque values (RTVs) were measured until the implant rotated inside the bone tissue, completely rupturing the bone-implant interface. These RTVs were then recorded for statistical analysis.

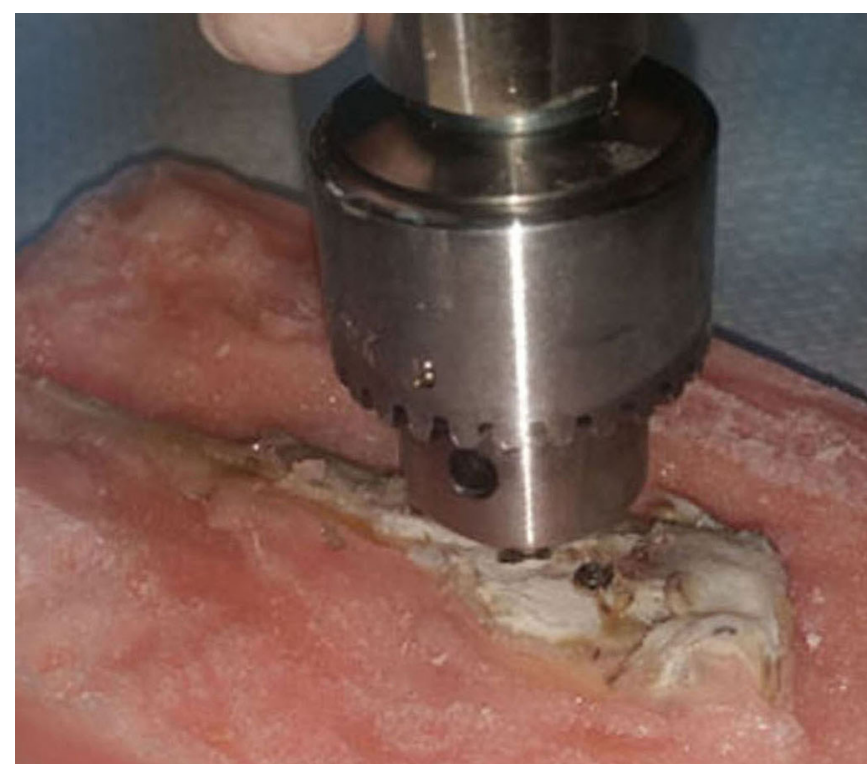

Figure 6. Application of RTT.

\subsection{Statistical Analysis}

The RFA values and RTVs were analyzed using the KruskalWallis and Mann-Whitney $U$ tests; SPSS (version 16.0; SPSS, Chicago, IL, USA) was used for the statistical analysis. Differences in ISQs were evaluated with the Wilcoxon signedrank test. A correlation analysis (Spearman) was used to determine the correlation of the RFAs and RTVs. Values of $p$ greater than .05 were considered statistically significant.

\section{RESULTS}

The means and standard deviations of the ISQs and RTVs for all groups are presented in Table 1 . The highest mean ISQ values was seen in the group of pneumatic crown remover before crown removal $(66.9 \pm 8.3)$, and the lowest was detected in group of spring-loaded crown remover after crown removal $(51.5 \pm 29.09)$. Analysis of the data also revealed that no significant difference in ISQ values was measured after crown removal in either with a diamond bur or pneumatic crown remover $(p=0.677$ and $p=0.918$, respectively). However, there was a statistically significant difference in ISQ values after crown removal in group of spring-loaded crown remover $(p=0.008)$.
Table 1: Mean and standard deviations (SD) of the ISQ values and RTVs of the groups

\begin{tabular}{|l|l|l|l|}
\hline Groups & $\begin{array}{l}\text { ISQ values before } \\
\text { crown removal }\end{array}$ & $\begin{array}{l}\text { ISQ values after } \\
\text { crown removal }\end{array}$ & $\begin{array}{l}\text { Reverse } \\
\text { torque values } \\
\text { (N.cm) }\end{array}$ \\
\hline Group Bur & $64.3^{\mathrm{a}}(12.43)$ & $64.1^{\mathrm{a}}(17.43)$ & $18.7^{\mathrm{A}}(7.29)$ \\
\hline $\begin{array}{l}\text { Group Spring- } \\
\text { loaded }\end{array}$ & $65.3^{\mathrm{a}}(14.53)$ & $51.5^{\mathrm{b}}(29.09)$ & $14^{\mathrm{A}}(8.06)$ \\
\hline Group Pneumatic & $66.9^{\mathrm{a}}(8.3)$ & $65.2^{\mathrm{a}}(11.6)$ & $18.7^{\mathrm{A}}(7.87)$ \\
\hline
\end{tabular}

For each horizontal row: values with small letters indicate no statistically significant difference ( $p>0.05)$

For each vertical column: values with capital letters indicate no statistically significant difference ( $p>0.05)$.

The lowest RTV was found in group of spring-loaded crown remover $(14 \mathrm{~N} . \mathrm{cm})$. Furthermore, diamond bur and pneumatic crown remover groups exhibited similar mean RTVs (18.7 N/ $\mathrm{cm}$ ). However, no significant difference in RTVs was detected between the groups according to the Mann-Whitney $U$ test results $(p>0.05)$. Moreover, Spearman analysis revealed a positive correlation between ISQ and RTV $(r=0.532)$.

\section{DISCUSSION}

Based on the results of the present study, the hypothesis that no difference exists in the ISQ of dental implants after various crown-removal procedures was partially accepted. Because, ISQ values presented significant differences after different crown removing procedures whereas, RTV did not change after crown removing procedures. There is very limited research about crown-removal procedures for implant retained single crowns. Worni et al. (7) carried out crownremoval procedures on 74 crowns that were cemented on dental implants in 21 patients. They found that, regardless of cement type (provisional or definitive), a pneumatic crown remover device can be safely applied for crown removal without technical complications. In addition, Polat Sağsöz et al. (14) investigated the effects of crown-removal procedures on 815 units of fixed partial dentures in 160 patients. They reported that a manual instrument resulted in marginal damage to the restorations. Furthermore, consistent with the results of the Worni et al. study (7), they found that pneumatic crown removers caused less marginal damage than did manual ones. In the present study, unlike the springloaded, back-action crown remover, the pneumatic crown remover had no adverse effect on the ISQ of dental implants. Thus, the results of the present study are in agreement with those of Worni et al. (7) and Polat Sağsöz et al. (14).

Nevertheless, in the literature, researchers have tried to establish the correlation between ISQ values and the percentage of BIC. Although RFA was presented as a sensitive method for detecting $\mathrm{BIC} \%$, (15) some researchers found no correlation between ISQ and BIC\% (16-19). However, a positive correlation between RTVs and BIC\% has been found (20).Furthermore, Bischof et al. (21) advocated that RTVs are more reliable than ISQs when evaluating bone-implant interface. Thus, although clinically not applicable, RTT was also used in the present study to assess the implant stability 
and osseointegration. Based on the results of the present study, a linear relationship was seen between ISQ and RTV. This result is in accordance with that of Gehrke and Marin (22), who reported a relative correlation between ISQ and RTV for each time period $(6,8$, and 12 weeks after implantation) in their groups. Contrarily, Bischof et al. (21) and Cehreli et al. (23) found no linear correlation between ISQ and RTV. At this stage, the important question is which method should primarily be considered. RTT enables measurement of the strength of the interface between bone and implant in terms of shear; RFA detects the stability during bending (24). The bending force simulates the clinical situation more closely than does the shear force based on data about force, direction, and stiffness of the bone-implant junction.

One of the limitations of this study is that metal crowns (instead of metal-ceramic crowns) were cemented on the abutments. Thus, the bur cutting was performed on only one layer-metal. However, a ceramic layer would be more easily removed by burs than a metal layer would. Therefore, this limitation may not affect the results of the present study. On the other hand, future investigations could focus on the effect that the removal procedure has on the ISQ and RTV values of dental implants in FPDs that are retained with multiple implants and those that have a monoblock design.

\section{CONCLUSION}

Within the limitations of the present study, crown-removal procedure has negative effect on the ISQ values of dental implants. Clinicians may primarily consider using bur cutting method for removing of the crowns because the SL group had a lower ISQ, and lower RTV's than the other 2 groups.

\section{Acknowledgements}

The authors do not have any financial interest in the companies whose materials are discussed in this article. This investigation was supported in part by the Sakarya University Scientific Research Project. This study was presented as an oral presentation at the annual meeting of the 22th International Scientific Congress of Turkish Prosthodontics and Implantology Association, 12-15 November, 2015, Antalya, Turkey.

\section{REFERENCES}

[1] Ma S, Fenton A. Screw - versus cement-retained implant prostheses: a systematic review of prosthodontic maintenance and complications. Int J Prosthodont. 2015;28:127-145.

[2] Mehl C, Harder S, Schwarz D, Steiner M, Vollrath O, Kern M. In vitro influence of ultrasonic stress, removal force preload and thermocycling on the retrievability of implant-retained crowns. Clin Oral Implants Res. 2012;23:930-937.

[3] Lemos CA, de Souza Batista VE, Almeida DA, Santiago Júnior JF, Verri FR, Pellizzer EP. Evaluation of cement-retained versus screw-retained implant-supported restorations for marginal bone loss: A systematic review and meta-analysis. J Prosthet Dent. 2016;115:419-427.
[4] Sailer I, Mühlemann S, Zwahlen M, Hämmerle CH, Schneider D. Cemented and screw-retained implant reconstructions: a systematic review of the survival and complication rates. Clin Oral Implants Res 2012;23(Suppl 6):163-201.

[5] Garg P, Pujari M, Prithviraj DR, Khare S. Retentiveness of various luting agents used with implant-supported prosthesis: an in vitro study.J Oral Implantol. 2014;40:649-654.

[6] Akin H, Guney U. Effect of various surface treatments on the retention properties of titanium to implant restorative cement. Lasers Med Sci 2012;27:1183-1187.

[7] Worni A, Gholami H, Marchand L, Katsoulis J, Mericske-Stern $\mathrm{R}$, Enkling N. Retrievability of implant-supported crowns when using three different cements: a controlled clinical trial. Int J Prosthodont. 2015;28:22-29.

[8] Mehl C, Harder S, Wolfart M, Kern M, Wolfart S. Retrievability of implant-retained crowns following cementation. Clin Oral Impl Res. 2008;19:1304-1311.

[9] Ormianer Z, Schiroli G. Maxillary single-tooth replacement utilizing a novel ceramic restorative system: results to 30 months. J Oral Implantol. 2006;32:190-199.

[10] Freitas AC Jr, Bonfante EA, Martins LM, Silva NR, Marotta L, Coelho PG. Reliability and failure modes of anterior singleunit implant-supported restorations. Clin Oral Implants Res. 2012;23:1005-1011.

[11] Mangano C, Mangano F, Piattelli A, lezzi G, Mangano A, La Colla L. Prospective clinical evaluation of 307 singletooth morse taper-connection implants: amulticenter study. Int J Oral Maxillofacial Implants 2010;25:394-400.

[12] Pjetursson BE, Bragger U, Lang NP, Zwahlen M. Comparison of survival and complication rates of tooth-supported fixed dental prostheses (FDPs) and implant-supported FDPs and single crowns (SCs). Clin Oral Implants Res 2007;18(Suppl 3):97-113.

[13] Janardanan K, Varkey VK, Lovely M, Anuroopa A. Coronal disassembly systems and techniques: An overview. J Interdiscip Dentistry 2014;4:33-40.

[14] Polat Sağsöz N, Yanıkoğlu N, Aladağ Li, Ozdemir H, Ciftci H. The investigation of reasons for removal of fixed prosthetic restorations and comparison of traditional removal method with KaVo CORONAflex restoration remover. Atatürk Üniv Diş Hek Fak Dergisi 2014;24:378-385. (Turkish)

[15] Sennerby L, Persson LG, Berglundh T, Wennerberg A, Lindhe J. Implant stability during initiation and resolution of experimental periimplantitis: an experimental study in the dog. Clin Implant Dent Relation Res. 2005;7:136-140.

[16] Ito Y, Sato D, Yoneda S, Ito D, Kondo H, Kasugai S. Relevance of resonance frequency analysis to evaluate dental implant stability: simulation and histomorphometrical animal experiments. Clin Oral Implants Res. 2008;19:9-14.

[17] Al-Nawas B, Groetz KA, Goetz H, Duschner H, Wagner W. Comparative histomorphometry and resonance frequency analysis of implants with moderately rough surfaces in a loaded animal model. Clin Oral Implants Res. 2008;19:1-8.

[18] Abrahamsson I, Linder E, Lang N. Implant stability in relation to osseointegration: an experimental study in the Labrador dog. Clin Oral Implants Res 2009;3:313-318.

[19] Abdel-HaQ J, Karabuda ZC, Arısan V, Mutlu Z, Kurkcu M. Histologic and histomorphometric evaluation of a hydrophilic blasted and acid-etched implant: an experimental study in sheep tibia. İstanbul Üniv Diş Hek Fak Derg 2010;44:141-152. (Turkish) 
[20] Ivanoff CJ, Sennerby L, Lekohm U. Influence of mono and bicortical anchorage on the titanium implants. A study in rabbit tibia. Int J Oral Maxillofac Surg. 1996;25:229-235.

[21] Bischof M, Nedir R, Moncler SS, Bernard JP, Samson J. Implant stability measurement of delayed and immediately loaded implants during healing - A clinical resonance frequency analysis study with SLA ITI implants. Clin Oral Implant Res 2004;15:529-539.

[22] Gehrke SA, Marin GW. Biolechanical evaluation of dental implants with three different designs: Removal torque and resonance frequency analysis in rabbits. Ann Anat. 2015;199:30-35.

[23] Cehreli MC, Karasoy D, Akca K, Eckert SE. Meta-analysis of methods used to assess implant stability. Int J Oral Maxillofac Implants 2009;24:1015-1032.

[24] Rasmusson L, Merdith N, Cho IH, Sennerby L. The influence of simultaneous versus delayed placement on the stability of titanium implants in onlay bone grafts - A histologic and biomechanic study in the rabbit. Int J Oral Maxillofac Surg 1999;28:224-231.

How to cite this article: Akin H, Unal Y, Yilmazer K. Effect of Different Crown Removing Procedures on the Implant Stability Quotient and Removal Torque Values of Dental Implants. Clin Exp Health Sci 2021; 11: 314-319. DOI: 10.33808/clinexphealthsci.789728 